\title{
Nutritional and amino acid contents of differently treated Roselle (Hibiscus sabdariffa L.)seeds
}

\begin{abstract}
The effects of sun-drying and boiling sun-drying on the nutritional composition of Roselle (Hibiscus sabdariffa L.) seeds, grown from Malaysia, were investigated. The treatments were raw freeze-dried Roselle seeds (RRS), sun dried Roselle seeds (DRS) and boiled sun-dried Roselle seeds (BRS). Protein, lipids and dietary fibre were found to be high in all the treatments. The seeds, regarded as by-product of Roselle processing had $57.3 \%$ moisture. Raw freeze-dried, sun dried and boiled sun-dried seeds contained $6.81 \%, 9.9 \%$ and $9.8 \%$ moisture; $35.4 \%, 33.5 \%$ and $30.6 \%$ protein; $27.2 \%, 22.1 \%$ and $29.6 \%$ lipids; $2.3 \%, 13.0 \%$ and $4.0 \%$ available carbohydrate; $25.5 \%, 18.3 \%$, and $19.2 \%$ total dietary fibre; and $7.4 \%$, $7.5 \%$ and $6.6 \%$ ash, respectively. The carbohydrate, protein, lipids and moisture of RRS were significantly different $(\mathrm{p}<0.05)$ from DRS and BRS. The predominant minerals in Roselle seeds were potassium (99-109 mg/100 g), magnesium (26-28 mg/100 g) and calcium (24-31 $\mathrm{mg} / 100 \mathrm{~g}$ ). The total dietary fibre of the seeds was within the acceptable range, with soluble and insoluble fibre ratios ranging from 1.2 to 3.3. The study detected 17 essential and nonessential amino acids. The seeds were rich in lysine (14-15 g/100 g), arginine (30-35 $\mathrm{g} / 100 \mathrm{~g})$, leucine (15.4-18.6 g/100 g), phenylalanine (11-12 g/100 g) and glutamic acid (21$24 \mathrm{~g} / 100 \mathrm{~g})$. The study indicated that Roselle seeds may serve as a potential source of functional ingredients.
\end{abstract}

Keyword: Roselle seeds; Differently treated seeds; Nutritional composition 